\title{
An Inductive Study on the Application of Tie-dye in Tang Dynasty
}

\author{
Yingli Sun ${ }^{1, *}$ Min Liu ${ }^{1}$ \\ ${ }^{1}$ School of Arts, Xi'an University of Science and Technology, Xi'an, Shaanxi 710000, China \\ *Corresponding author. Email: 307760833@qq.com
}

\begin{abstract}
The Tang dynasty was the most prosperous period for the development of tie-dye in ancient China. The tie-dye of this period was highly skilled, richly colorful and widely used. Its social function is also one of the important bases for the study of traditional tie-dye technology, so it is necessary to study it. This paper mainly uses the method of literature research and comparative research, with the help of scroll paintings, frescoes, figurines and other image data and documents, the application of the Tang dynasty's warping valerian was textual research, classification, induction and interpretation. Therefore, it makes up for the insufficiency and imperfection of the unearthed tie-dye and reflects the truth, fresh and complete application of tie-dye in the Tang dynasty.
\end{abstract}

Keywords: China's Tang dynasty, Tie-dye skill, Uses, Information.

\section{INTRODUCTION}

Tie-dye skill is one of the traditional textile dyeing techniques in ancient China. First with the help of needle, thread and other tools to use sewing, tying, knot and other ways to the fabric according to the pre-designed pattern to be tied, so that the dye can not completely penetrate, to prevent the purpose of dyeing. Then, the cloth is dyed. Finally, the thread can be removed to show a variety of unique patterns.

The history of tie-dye skills in China can be traced back to 3rd century BC, which not only has a long history, but also has a high production level, and developed to an unprecedented prosperity in Tang dynasty. Due to the economic prosperity of Tang dynasty, the rapid development of dyeing and weaving technology, the continuous improvement of weaving technology and the mass production of silk products, Therefore, the technique of tie-dye can be developed unprecedentedly in Tang dynasty. The fabric dyed by the tie-dye technique is gorgeous was brilliant in color and hazy in color, which has become a social fashion in Tang dynasty.

The tie-dye fabrics in Tang dynasty are not only artistic but also practical, and their practicality in life is one of the important bases for the study of traditional tie-dye skills. Since the mid-20th century, a large number of tie-dye clothes and fabrics in Tang dynasty have been found in China. Although the tie-dye fabrics are the most common, the overall retention is still small. Due to the environmental impact, the preservation is poor, and the intact objects of the Tang dynasty are extremely rare. Therefore, in order to restore the application of the Tang dynasty's objects in life truly, vividly and completely, this paper constructs them together with the help of contemporary image data, and makes up for the deficiency and incompleteness of the unearthed objects of the Tang dynasty. By means of mutual verification, this paper starts with the documents, objects and images of the Tang dynasty to enrich the knowledge system of the tiedye skills in the Tang dynasty.

\section{THE CHARACTERISTICS OF TIE- DYE IN TANG DYNASTY}

Due to the long time, inappropriate humidity and temperature in the preservation environment, color variation and natural damage of fabrics are common, and many tie-dye fabrics are fragments when unearthed, which affects the extraction of its core elements. The author draws on the scroll paintings, figurines, colored sculptures, three colors of the Tang dynasty, murals and other image materials and cultural relics related to tie-dye in the Tang dynasty. Through mutual confirmation and 
mutual complementation, we can provide more clues for people to understand the application of tie-dye skills of the Tang dynasty in daily life. There are also many images related to tie-dye in the Tang dynasty. Such as "Flying Apsaras of Dunhuang" in Cave 320 and "The Hanging House Chatting" in Cave 85 of Mogao Grottoes in Gansu Province. There are also such as "Han Xizai Evening Banquet", "Practicing and Working" and "Group portrait of Noblewomen" and other scroll paintings. The artistic forms represented by scroll paintings, figurines, colored sculptures, three colors of Tang dynasty and frescoes in Tang dynasty, they are all precious image data and historical annotations of the art of tie-dye.

From the substrate, the unearthed Tang dynasty tie-dye was mainly spun silk, and there were also fabrics such as leno, ghatpot, etc. Compared with fabrics of other dynasties, there were many kinds of substrates in Tang dynasty. The Silk Road is unimpeded, textile production went from a relatively independent production system in the Central Plain to extensive trade flows along the route. Economic prosperity, the progress of manufacturing technology, and the production of a large number of silk products have promoted the prosperity of tie-dye.

The four methods summarized by Wang include sewing, splinting, tying and tying. According to the process of tie-dye objects in Tang dynasty, there are three main techniques of tie-dye objects unearthed in Tang dynasty: sewing, splint and binding, among which the binding method is the most widely used, but the tie-dye objects made by knotting method have not been found yet.

Combining tie-dye objects and related images, we know that the patterns of the Tang dynasty's tiedye can be roughly divided into three types: flower patterns, dot patterns and geometric patterns. The tie-dye pattern of Tang dynasty is also reflected in the poetry of Tang dynasty, which mainly includes drunken eye print, roe print, a ball of flower print and the pattern of smoke and clouds.

In terms of color, the colors of the Tang dynasty were brilliant and colorful, preferring sfumato colors. Scholars have studied it in various historical periods. The cultivation and production methods of plant dyes such as bluegrass, safflower, gardenia and lithospermum erythrorhizon were introduced in the book by "Important Arts for the People's Welfare" Jia Sixie in Northern Wei Dynasty. It can be seen that the progress of dyeing technology at that time, the colors of fabrics were more abundant.
During the Sui and Tang Dynasties, dyeing technology achieved unprecedented development. On the basis of mastering the method of dyeing primary colors, overprinting is used to obtain different intermediate colors. There are as many as 24 colors of silk fabrics unearthed in Turpan. Therefore, the unearthed objects of Tang dynasty's tie-dye contain various colors, which can also prove the flourishing dyeing in Tang dynasty. Combined with the glaze color of the Tang tricolor in the same period, it can be seen that the use of multicolor tiedye in Tang dynasty should also have a certain scale.

\section{APPLICATION OF TIE-DYE IN TANG DYNASTY}

People's life in ancient times is closely related to the development of tie-dye skills. People are not only creators and successors of tie-dye skill, but also the users of tie-dye products. Therefore, the fabrics dyed by tie-dye skill had various uses, serving all aspects of people's life at that time, including daily clothes, daily necessities, religious activities, etc.

\subsection{Being Used for Clothing}

The tie-dyed fabric of clothing has been found in the physical objects of various dynasties. Because of its unique sfumato color, the tie-dye fabric has been favored by people in all dynasties. Especially in the Tang dynasty, in addition to the use of women's clothing tie-dye, many men's clothing is also tie-dye for decoration. During the Kaiyuan period (713-74), this kind of dress custom was defined as the etiquette system, and followed the Song Dynasty. ${ }^{1}$

A clay figurine of a woman wearing a long dress and a pullover knee-high was unearthed from the tomb of Princess Yongtai of the Tang dynasty in Shaanxi Province. It can be seen that there is a pattern of anti dyeing white flowers on the long shirt, and there is a dark sfumato effect in the center. It can be judged to be made of tie-dye.

In the painting of "Practicing and Working", a palace maid carrying a silk fan fanned the fire near the stove, wearing a blue robe and yellow rounded floral patterns as decorations. The outer edge of the rounded floral pattern and the lake blue ground permeate each other, and the junction is very fuzzy,

1. Zhang Daoyi: A Brief History of Printing and Dyeing in China, p. 24 
showing a halo dyeing effect. In the painting of "Lady of Guoguo Spring Outing", there is a similar twist in the painting of "Lady of Guoguo Spring Outing".

In the painting of "Ladies with head-pinnedflowers" (see "Figure 1"), a lady on the right of the picture is dressed in a red dress with large rounded floral patterns. The outer edge of the large rounded floral pattern is hazy, while the rounded flora pattern of the internall is very clear. It is speculated that the effect of the combination of pattern and embroidery. In this picture, there are also several long coats with light texture. The anti-dyeing white patterns on the tops are interlaced with each other, which have the effect of fainting and changing, and should be produced by the tie-dye skill.

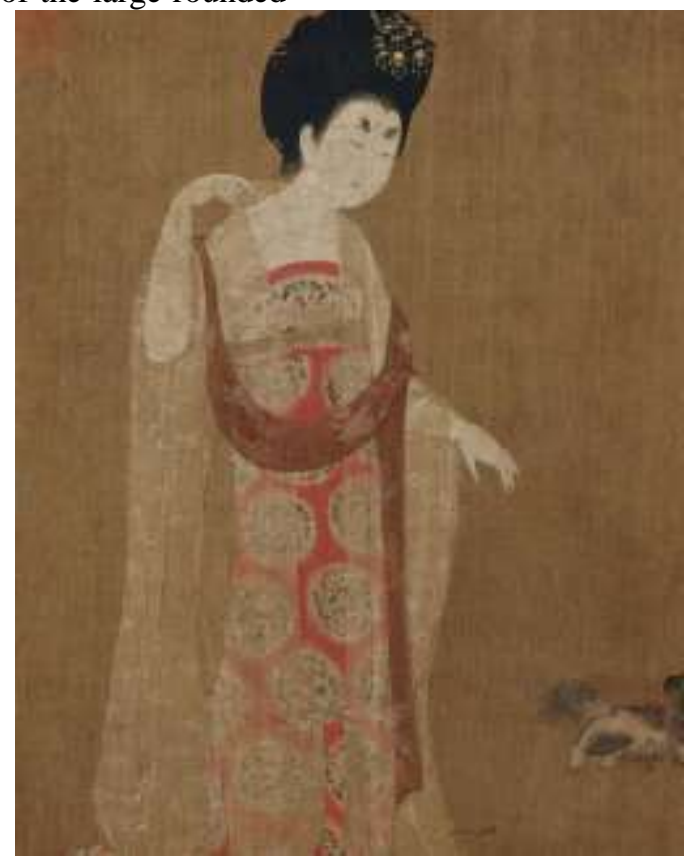

Figure 1 Zhou Fang Ladies with head-pinned-flowers.

The female figurines of the Tang dynasty were unearthed in Turpan, Xinjiang in $1973 .^{2}$ Its shawl is a piece of grass-green leno fabric, decorated with many white patterns in the shape of square dots. The pattern is very small. The size and shape of a single square dot are very similar to that of fish roe. Each square white dot has a small green spot in the center, and three dots form a pattern.

Based on the research of unearthed objects and image materials, it is founded that the tie-dye skill was widely used in clothing, such as clothes, trousers, skirt, shawl, robe, hat, belt, hairband, etc. For example: "Practicing and Working" appeared with tie-dye decoration of the hair band.

\subsection{Being Used for Daily Necessities}

It was also widely used in common daily necessities, such as screens, valances, pillowcases,

2. Mu Shunying, editor-in-chief: Ancient Art in Xinjiang, China, Color Picture 382, Xinjiang Fine Arts Photography Publishing House, 1994. quilts, bed sheets, etc. It reflects the social life fashion and aesthetic taste at that time.

In the painting of "Han Xizai Evening Banquet", there are many articles of daily use dyed with the skille of tie-dye. There are two beds on the picture, one of which is covered with a red valance and decorated with large yellow circles. The other bed was covered with a brown-black valance with large white circles. The patterns on two valances are hazy, obviously tie-dye. There is a lake and blue sheets under the red valances, and there are white big dots on it, which is the effect of dyeing prevention by using the technique of tie-dye. In addition to the size and overall arrangement of the valance is very similar to the pattern, this pattern may be mentioned in ancient books. In this bed there is also a blue pillow with yellow rounded circles arranged in a criss-crossing pattern, apparently also tie-dyed. In addition, the bed with brown-black valance is covered with a red quilt, decorated with white plum blossom patterns. The pattern is blurred and tiedyed. In "Party for Scholars", In addition to the women's clothing on the obvious pattern, also 
found in its cushion pattern of red ground and white flowers.

\subsection{Being Used for Religious}

In addition to playing a wide decorative role in daily life, tie-dye skill also penetrates into all aspects of social life, and even serves for religious activities and sacrifice activities.

First of all, there are many tie-dye prayer flags used for religion, so there are a lot of reports about the unearthed of these prayer flags in Dunhuang and other Buddhist holy places. In 1965, more than 60 colored prayer flags of different types were discovered in Cave 130, Cave 122 and Cave 123 of Mogao Grottoes in Dunhuang. Among them, there are many tie-dyed prayer flags, among which the "Silk Tie-dyed Sutra Flag" (see "Figure 2") collected by Dunhuang Academy is one of them. With a length of $164 \mathrm{~cm}$ and a width of $13.5 \mathrm{~cm}$, this collection is the most representative and relatively well-preserved tie-dye work of the Tang dynasty. The strip is composed of six segments intersected by square spun silk in green, purple and yellow fields. Only the third section is batik yellow silk, the rest is tie-dye silk, the first and fifth sections are green silk, the second, fourth and sixth sections are purple silk. There are white spots and rhombiclattice on the top of them. They are typical Fangsheng patterns, showing the effect of fainting and changing.

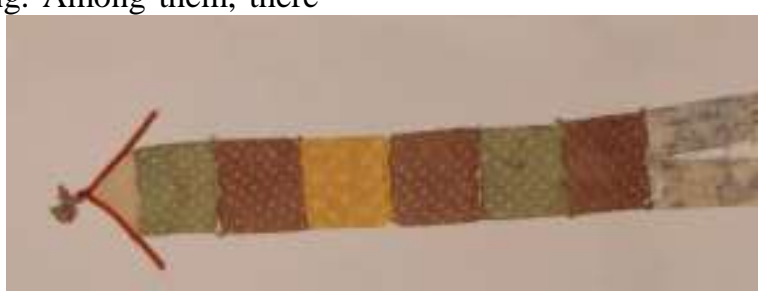

Figure 2 Silk tie-dyed sutra flag.

Secondly, tie-dye is also used for religious clothing. The painting of "Flying Apsaras of Dunhuang" in cave 320 of Mogao Grottoes, there are two flying Apsaras on the left and right respectively. The ribbons on their bodies are all reddish brown, and the white circular patterns on them have sfumato effect. They are very similar to the patterns of the white pattern on the female figurines unearthed in Astana. The three white rings form a group, and the arrangement is very regular. In addition, tie-dye also appears in "Illustration of Raudraksa "in Cave 196 of the Mogao Grottoes in Dunhuang. In the painting, the Bodhisattva on the lotus seat is covered with a long dark brown mantle. The mantle is decorated with a large round flower pattern of light brown, which are regularly distributed on the Cape, and the effect of halo dyeing is obvious. There is also a blue buddha's garment under his mantle. There are light brown round patterns on the hem of the Buddha's clothes, which are closely distributed. The outline curve of the outside is fuzzy, and the effect of halo dyeing is obvious. In addition, several monks stand to the right of the bodhisattva, wearing kasayas of various colors, all of which are tie-dyed. Several of the kasayas have a number of rounded floral patterns. The above mentioned Buddhist clothing and kasaya can reflect the application of tie-dye in religious clothing to a certain extent.
Finally, tie-dye in Tang dynasty can also be directly used as offerings. According to the records in Travel Notes in The Tang dynasty for Learning Buddhism, tie-dye was used as sacrificial offerings during long sea voyages. This document is a strong evidence that tie-dye was used as sacrificial offerings to worship the gods of heaven and earth. ${ }^{3}$ The application of tie-dye in religious and sacrificial activities expresses people's reverence and piety.

\section{CONCLUSION}

In the Tang dynasty, people lived a comfortable and prosperous life. Under the influence of the economic prosperity and cultural integration of the regions along the Silk Road, tie-dye showed the characteristics of magnificent color, light and elegant, full shape and rich. According to the analysis of painting, tri-coloured glazed pottery of the Tang dynasty, frescoes and so on, tie-dye in the Tang dynasty not only possesses artistic, but also has practical.

The application of tie-dye in the Tang dynasty was far more than these. The examples presented in this paper are only a few of the unearthed cultural

3. Li Dingxia: Notes on the Journey to the Tang Dynasty to Seek Dharma, Notes on Xu Denan, Hebei: Huashan Literature and Art Publishing House, 2007, p. 155. 
relics and image data. In addition, there are many pieces of cultural relics and images that cannot be accurately identified. Many of the uses described in the literature are not identified in the physical and graphical data. Whether it was used in a large area, or local decoration, whether it was worn on the body, or integrated into life, whether it was used in religion or offered sacrifices to gods, all showed the situation that tie-dye was widely used at that time, which indirectly reflected the heyday of tie-dye in the Tang dynasty.

\section{AUTHORS' CONTRIBUTIONS}

Yingli Sun collected the cultural relics and video datum, and Min Liu wrote the manuscript.

\section{REFERENCES}

[1] Huang Nengfu. Chinese Printing and Dyeing History [M]. Beijing: Zhonghua Book Company, 1962.

[2] Yang Jianjun. Tie-dye Art Design Course [M]. Beijing: Tsinghua University Press, 2010.

[3] Shen Congwen. Research on Chinese Ancient Clothing [M]. Shanghai: Shanghai Bookstore Press, 2011.

[4] Zhang Daoyi. The History of Chinese Printing and Dyeing [M]. Nanjing: Jiangsu Fine Arts Publishing House, 1987.

[5] Shen Congwen. On the historical development of dyed valerian - white calico with blue background [J]. Cultural Relics, 1958 (9).

[6] Wang Yu. Ancient Chinese Valerian Craft [J]. Archaeology and Cultural Relics, 1986 (1).

[7] Jin Shaoping, Wang Lu. Chinese Ancient Hanging Valerian and Its Cultural Connotation $[\mathrm{J}]$. Journal of Yantai University, 2014 (3).

[8] Mu Shunying, editor-in-chief: Ancient Art in Xinjiang, China, Color Picture 382, Xinjiang Fine Arts Photography Publishing House, 1994.

[9] Li Dingxia: Notes on the Journey to the Tang dynasty to Seek Dharma, Notes on Xu Denan, Hebei: Huashan Literature and Art Publishing House, 2007.

[10] Shang Gang. Tang dynasty Poetry and Arts and Crafts [J]. Decoration, 2017 (3).
[11] ZHANG Ning. Historical Development and Research Status of Silk Road Valerian Dyeing Technique $[\mathrm{J}]$. Art Appreciation, 2018,(03):59-60. 